\title{
Pemanfaatan dan Penggunaan Secara Rasional Tanaman Obat Tradisional Sebagai Terapi Swamedikasi di Kampung KB, Magersari Kota Magelang
}

\author{
Ni Made Ayu Nila Septianingrum, Fitriana Yuliastuti, Widarika Santi Hapsari \\ Program Studi Farmasi Fakultas Ilmu Kesehatan, Universitas Muhammadiyah Magelang \\ nimadeayunila@ummgl.ac.id, fitrianayuliastuti@ummgl.ac.id, widarika@ummgl.ac.id
}

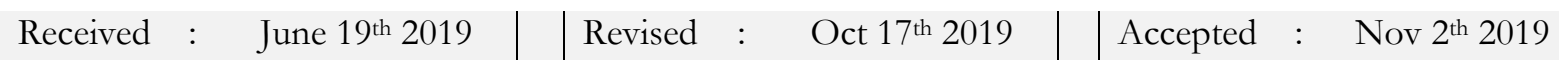

\begin{abstract}
Self-medication (swamedikasi) is one of the ways that many people do to overcome the symptoms of the disease before getting help from the health center. Magersari village has 13 hamlets (RW) with a total population of 7.728 society and has the advantage as the hometown of family planning (KB). Most large residents in kampung $K B$ magersari consume traditional drugs without knowing the appropriate doses. It supports the activities need of devotion is that people rationally in taking conventional medicine. The purpose of this service is to increase knowledge and skills about the use of plants environment around that have potential as a drug of mothers in kampung KB, magersari, Magelang. The method used participatory rural appraisal (PRA). The activity was carried out for three months by socialization to the head of kampung KB. Besides, a series of FGD activities, an increase of community capacity of kampung KB through training and practice to assist in implementing therapy swamedikasi. As a result, $K B$ members received additional information about the properties and functions of Indonesia's natural plants partly already presented in the form of pocketbooks and presentations that can be used as one of the sources of information for swamedikasi. Besides, they were able to implement swamedikai to exploit and use traditional medicine through still in a simple form.
\end{abstract}

Keyword: Traditional Medicinal Plants, Self-Medication Therapy (Swamedikasi), Participatory Rural Appraisal (PRA).

\section{Pendahuluan}

Pembangunan kesehatan di Indonesia bertujuan untuk meningkatkan kesadaran, kemauan, dan kemampuan hidup sehat bagi setiap orang agar terwujud derajat kesehatan masyarakat yang setinggi-tingginya. ${ }^{1}$ Kementrian Kesehatan memiliki visi masyarakat sehat yang mandiri dan berkeadilan dengan misi untuk meningkatkan derajat kesehatan masyarakat, melindungi kesehatan masyarakat, menjamin ketersediaan dan pemerataan kesehatan, serta menciptakan tata kelola kepemerintahan yang baik. Strategi yang dilakukan untuk mencapai hal tersebut ialah dengan cara meningkatkan pelayanan kesehatan yang merata, terjangkau, bermutu dan berkeadilan, serta berbasis bukti, dengan pengutamaan pada upaya promotif dan preventif. Salah satu cara untuk

${ }^{1}$ Kementerian Kesehatan, "Rencana Strategis Kementerian Kesehatan,” Jakarta. Kementerian Kesehatan (2015).

Volume 3, Number 2, November 2019|208

Penggunaan Obat Rasional Dan Pemanfaatan Tanaman Obat Tradisional Sebagai Terapi Swamedikasi (Pengobatan Sendiri) Di Kelurahan Magersari Kota Magelang.

Ni Made Ayu Nila Septianingrum, Fitriana Yuliastuti, Widarika Santi Hapsari 


\section{ENGAGEMENT}

Lurnal Pengabdian Kepada Masyarakat

ISSN : 2579-8375 (Print)

ISSN : 2579-8391 (Online)
This work is licensed under a Creative Commons

Attribution-ShareAlike 4.0 International License.

CC BY SA

melakukan upaya preventif dan kuratif dapat dilakukan dengan melakukan pelayanan kesehatan tradisional ${ }^{2}$. Riset Kesehatan Dasar 2010 menyebutkan bahwa 59,12\% penduduk semua kelompok umur, laki-laki dan perempuan, baik di pedesaan maupun diperkotaan menggunakan produk obat tradisional asli Indonesia (jamu). Kekayaan hayati Indonesia berjumlah sekitar 30.000 spesies dan sebanyak 1.600 jenis tanaman obat memiliki potensi sebagai produk ramuan kesehatan tradisional atau pada gilirannya sebagai obat modern.

Kegiatan ini sejalan dengan program yang dicanangkan oleh Dinas Kesehatan Kota Magelang tentang pemanfaatan tanaman alam sebagai upaya terapi baik pencegahan maupun pengobatan untuk diri sendiri (swamedikasi). ${ }^{3}$ Pemerintah mengharapkan agar masyarakat mengutamakan tanaman alam sebagai terapi utama dalam melakukan swamedikasi dibandingkan menggunakan obat-obatan sintesis. Penggunaan tanaman alam yang memiliki potensi sebagai obat tidak boleh digunakan sembarangan walaupun lebih aman dibandingkan dengan obat sintesis. Masyarakat lebih banyak meyakini bahwa obat-obat tradional tidak ada efek samping sehingga tidak memperhatikan dosisnya. Masyarakat dapat memanfaatkan tanaman obat tersebut dengan cara menanam sendiri disekitar rumah, sehingga jika diperlukan dapat dengan mudah diperoleh.

Kelurahan Magersari terletak di tengah kota Magelang terdiri dari 13 RW dengan jumlah penduduk 7.728. Magersari memiliki keunggulan berupa Kampung Keluarga Berencana (KB). Sebagian besar warga di kampung ini mengenal obat tradisional dalam bentuk jamu dan mengkonsumsinya tanpa dosis yang tepat. Warga perlu diberikan pemaparan tentang kemanfaatan, pengolahan, pemberdayaan dan pemakaian obat tradisional yang tepat. Kegiatan yang akan dilakukan mencakup pemanfaatan lahan sempit sebagai media tanam tanaman obat, diharapkan dengan adannya tanaman obat masyarakat bisa memanfaatkan secara maksimal fungsi dan khasiat dari tanaman obat tersebut jika ditanam disekitar rumah atau lingkungan.

\section{Metode}

Pengabdian masyarakat ini menggunakan pendekatan Participatory Rural Apraissal (PRA) ${ }^{4}$ yang menekankan pemberdayaan kerterlibatan masyarakat dalam seluruh kegiatan yang dilaksakan.

\footnotetext{
2 Kementerian Kesehatan RI, Peraturan Pemerintah RI No. 103 Tabun 2014 Tentang Pelayanan Kesehatan Tradisional (Indonesia, 2014).

${ }^{3}$ Fitriana Yuliastuti, Widarika Shanti Hapsari, and Tria Mardiana, "GeMa CerMat (Gerakan Masyarakat Cerdas Menggunakan Obat) Bagi Guru Sekolah Dasar Kecamatan Magelang Selatan Kota Magelang," Community Empowerment 3, no. 2 (October 29, 2018): 34-37.

${ }^{4}$ Robert Chambers, "The Origins and Practice of Participatory Rural Appraisal," World development 22, no. 7 (1994): 953-969.
} 


\section{ENGAGEMENT}

Lurnal Pengabdian Kepada Masyarakat

ISSN : 2579-8375 (Print)

ISSN : 2579-8391 (Online)
This work is licensed under a Creative Commons

Attribution-ShareAlike 4.0 International License.

CC BY SA

Kegiatan selama 3 (tiga) bulan dengan melibatkan partisipasi masyarakat. Kegiatan dengan pendekatan PRA ini pertama diawali dengan sosialisasi tentang kegiatan yang dilaksanakan kepada ibu-ibu kader dan warga kampung KB kelurahan Magersari Kota Magelang dan pemberian materi tentang tanaman obat tradisional. Kegiatan yang kedua, FGD dan peningkatan kapasitas melalui Acbieve Motivation Training yang diberikan kepada mitra untuk memotivasi mitra dalam mengimplementasikan swamedikasi. Komunitas yang terdiri dari kelompok ibu-ibu kader dan warga kampung KB. Dalam implementasinya, masyarakat didampingi untuk dapat mengelompokkan masing-masing golongan obat tradisional dan contoh obatnya. Hal tersebut dilakukan pada saat sebelum dan setelah diskusi kelompok. Kegiatan ketiga dilakukan pelatihan pembuatan jamu yang berasal dari simplisia kering (tanaman yang dikeringkan). Manfaatnya untuk meningkatkan pemahaman dan pendapatan masyarakat dari segi ekonomi. Warga juga dibekali dengan praktek cara penanaman bibit tanaman obat tradisional dihalaman rumah. Hari terakhir yang dilakukan pendampingan untuk implementasi swamedikasi. Selain itu, Tim juga melakukan pendampingan dengan cara mengunjungi beberapa rumah warga untuk mengetahui pemanfaatan dan penanaman tanaman obat tradisional di rumah-rumah warga.

\section{Hasil dan Diskusi}

Pelaksanaan kegiatan pengabdian di kampung KB Kelurahan Magersari dilakukan selama tiga bulan dimulai dari perijinan hingga pendampingan. Kegiatan pendampingan yang dilakukan pada kader-kader PKK dan warga kampung KB Kelurahan Magersari. Inti kegiatan ini adalah memberikan edukasi ke masyarakat baik secara teori maupun praktek tentang obat tradisional yang dapat digunakan sebagai swamedikasi. Program yang dilakukan ini sebelumnya telah dilakukan pendekatan ke masyarakat mengenai masalah apa saja yang ada d imasyarakat yang berhubungan dengan kesehatan. Salah satu masalah yang perlu penanganan khusus di masyarakat ialah tentang obat-obat tradisional. Hasil kajian Yulianto ${ }^{5}$ di daerah Klaten menyatakan bahwa masyarakat memiliki pengetahuan yang kurang tentang manfaat tumbuhan obat keluarga (TOGA) atau obat tradisional sehingga perlu penyuluhan kepada warga tentang manfaat dan pemanfaatan TOGA dalam kehidupan sehari-hari. Selain itu, pemerintah kota Magelang mencanangkan untuk menggunakan obat tradisional sebagai terapi preventif dan pengobatan sebelum beralih ke obat sintesis.

\footnotetext{
${ }^{5}$ Susilo Yulianto, "Pengetahuan Masyarakat Tentang Taman Obat Keluarga Di Nglinggi, Klaten Selatan,” Jurnal Kebidanan dan Kesehatan Tradisional 1, no. 2 (2016).
}

Volume 3, Number 2, November 2019| 210 Penggunaan Obat Rasional Dan Pemanfaatan Tanaman Obat Tradisional Sebagai Terapi Swamedikasi (Pengobatan Sendiri) Di Kelurahan Magersari Kota Magelang. Ni Made Ayu Nila Septianingrum, Fitriana Yuliastuti, Widarika Santi Hapsari 


\section{ENGAGEMENT}

Lurnal Pengabdian Kepada Masyarakat

ISSN : 2579-8375 (Print)

ISSN : 2579-8391 (Online)
This work is licensed under a Creative Commons

Attribution-ShareAlike 4.0 International License.

CC BY SA

Kegiatan pertama yang dilakukan ialah sosialisasi dan pemberian materi tentang tanaman obat yang dapat digunakan sebagai terapi swamedikasi, apa saja khasiatnya dan bagaimana cara pengolahannya serta diskusi dengan warga kampung KB. Sebelum kegiatan sosialisasi warga diberikan form untuk menggolongkan obat tradisional, kemudian diberikan paparan tentang tanaman obat tradisional dengan pendekatan achive motivation training. Dari kegiatan ini, komunitas dampingan memiliki semangat untuk belajar tentang cara untuk pemilahan dan menggolongkan obat tradisional.

Kegiatan kedua dilakukan dengan menggunakan Metode achive motivation training. Dalam kegiatan komunitas dampingan diajak berdiskusi dalam bentuk FGD dengan membentuk kelompok-kelompok kecil. Hasil kegiatan ini didapatkan bahwa warga kampung KB telah memiliki pemahaman bahwa pada awalnya jamu sebagai golongan obat tradisional, namun secara bertahap mereka mendapat informasi jika obat tradisional yang sering dikonsumsi berasal dari tanaman obat baik yang masih segar, simplisia maupun dalam bentuk yang sudah dikemas. Selain itu, wargan Kampung KB juga telah memiliki peningkatan pemahaman dan pengetahuan tentang golongan obat tradisional.

Kegiatan di atas sejalan dengan hasil yang diperoleh oleh Siska Mayang Sari ${ }^{6}$ tentang pengetahuan warga mengenai Tanaman Obat Keluarga di Kelurahan Tangkerang Labuai, bahwa pengetahuan warga akan meningkat jika ada perlakuan sebelumnya. Warga menjadi tahu bahwa dalam obat tradisional memiliki penggolongan masing-masing berdasarkan tahapan uji efikasinya dan keamananya. Penggolongan obat ini perlu diketahui warga, karena tidak semua obat tradisional aman digunakan. Hal tersebut bergantung dari penyakit yang diderita, obat yang dikonsumsi dan dosis yang digunakan. Pemahaman warga yang baik tentang obat tradisional dapat mendukung pelaksanaan swamedikasi menggunakan tanaman tradisional secara aman.

Hasil penelitian riset kesehatan dasar (Riskesdas) Kementerian Kesehatan RI $2010^{7}$ menyatakan bahwa sebanyak 59.12\% masyarakat mengkonsumsi jamu pada semua kalangan usia. Bentuk sediaan jamu yang paling banyak disukai masyarakat adalah cair kemudian bentuk seduhan (serbuk), rebusan (rajang), dan bentul pil, kapsul atau tablet. Bentuk sediaan cair lebih banyak disukai masyarakat contohnya adalah jamu-jamu gendong yang siap minum. Sebagian besar masyarakat mengkonsumsi tanaman alam Indonesia tanpa menggunakan dosis yang tepat, warga hanya menggunakan takaran secukupnya, misalnya sebanyak satu genggam tangan atau beberapa

\footnotetext{
${ }^{6}$ Siska Mayang Sari and Tengku Abdur Rasyid, "Pemanfaatan Tanaman Obat Keluarga (Toga) Pada Masyarakat," Dinamisia: Jurnal Pengabdian Kepada Masyarakat 3 (2019).

7 Badan Litbang Kesehatan, “Laporan Riskesdas 2010,” Jakarta Badan Litbang Kesehat (2010).
}

Volume 3, Number 2, November 2019| 211 Penggunaan Obat Rasional Dan Pemanfaatan Tanaman Obat Tradisional Sebagai Terapi Swamedikasi (Pengobatan Sendiri) Di Kelurahan Magersari Kota Magelang. 


\section{ENGAGEMENT}

Lurnal Pengabdian Kepada Masyarakat

ISSN : 2579-8375 (Print)

ISSN : 2579-8391 (Online)
This work is licensed under a Creative Commons

Attribution-ShareAlike 4.0 International License.

CC BY SA

helai daun. Obat yang berbahan dasar dari tanaman tradisional walaupun dipandang lebih aman penggunaanya dibandingkan obat-obatan kimia akan tetap memberikan efek samping yang merugikan bagi pengguna jika tidak digunakan sesuai dosis yang tepat dan indikasi yang sesuai. Penggunaan obat kimia dan herbal secara bersamaan dapat memberikan efek samping karena terjadi interaksi antara kandungan obat sintesis dengan kandungan dari tanaman herbal tersebut, sehingga diperlukan jeda waktu antara mengkonsumsi obat sintesis dengan obat herbal. Lima besar tanaman obat yang paling banyak dikonsumsi masyarakat Indonesia ialah jahe (50.36), kencur (48.77), temulawak (39.65), meniran $(13,93)$, pace $(11.17 \%)$ dan sisanya sebanyak $(72.51 \%)^{8}$ menggunakan tanaman obat tradisional lainnya.

Hasil studi pendahuluan Tim, ditemukan data bahwa rata-rata warga Magersari mengkonsumsi obat herbal untuk penyakit masuk angin, osteoarthritis, kolesterol, diabetes melitus, asam urat, darah tinggi, hepatitis dan nyeri pada tubuh. Penggunaan obat-obat sintesis dan tradisional untuk penyakit tersebut rutin dilakukan setiap harinya, sehingga warga perlu pengetahuan lebih dalam mengenai cara mengkonsumi, menyimpan dan mengolah obat tradisional jika digunakan berdampingan dengan obat kimia.

Kegiatan selanjutnya adalah praktek pembuatan jamu. Cara pengolahan akan mempengaruhi efek dari tanaman obat tersebut, jika cara pengolahanya salah maka dapat merugikan bagi yang mengkonsumsi. Salah satu pengolahan tanaman obat yang mudah ialah dengan dikeringkan. Diawali dengan Pengeringan pada tanaman obat memiliki banyak keuntungan diantaranya ialah dapat disimpan lebih lama pada wadah yang sesuai, mengurangi penurunan mutu sebelum diolah lebih lanjut, mudah dalam pengangkutan serta menaikan nilai ekonomi dari tanaman tersebut. Tanaman obat yang dikeringkan disebut simplisia, pengeringan simplisia dapat dilakukan dengan menggunakan lemari pengering atau dibawah sinar matahari langsung yang ditutupi oleh kain tipis bewarna hitam. Sudah ada beberapa warga yang berpartisipasi dalam kegiatan ini melakukan hal tersebut, akan tetapi mereka mengeringkan tanamanya langsung dibawah sinar matahari sampai kering tanpa dilapisi kain hitam tipis. Hal tersebut dapat berpotensi merusak kandungan zat dalam simplisia tersebut sehingga tidak akan memberikan efek yang maksimal jika dikonsumsi.

Penyimpanan simplisia juga tidak boleh asal disimpan diwadah tertutup. Beberapa warga yang sudah menghasilkan simplisia kering biasanya menyimpanya dalam wadah berupa karung atau plastik. Wadah penyimpanan yang baik salah satunya berbahan dasar kaca karena dapat menyimpan simplisia lebih lama dan awet sehingga tidak mudah menjamur. Suhu yang dianjurkan antara 8-

${ }^{8}$ Kementrian Kesehatan, PMK Nomor 6 Tabun 2016 Tentang Formularium Obat Herbal (Indonesia, 2016).

Volume 3, Number 2, November 2019| 212 Penggunaan Obat Rasional Dan Pemanfaatan Tanaman Obat Tradisional Sebagai Terapi Swamedikasi 


\section{ENGAGEMENT}

Lurnal Pengabdian Kepada Masyarakat

ISSN : 2579-8375 (Print)

ISSN : 2579-8391 (Online)
This work is licensed under a Creative Commons

Attribution-ShareAlike 4.0 International License.

CC BY SA

$15^{\circ} \mathrm{C}$. Melalui pendampingan ini, terjadi peningkatan pengetahuan tentang cara yang benar untuk menghasilkan simplisia yang baik dan cara penyimpananya. Selain itu, mereka juga menjadi tahu bahwa obat tradisional tidak dianjurkan untuk diberikan pada penderita dalam keadaan gawat darurat dan atau dalam keadaan yang potensial membahayakan jiwa. Wadah untuk merebus simplisia tidak boleh menggunakan logam, kecuali stainless steel, sebaiknya menggunakan wadah yang terbuat dari kaca, keramik atau porselen agar tidak merusak kandungan dalam simplisia itu sendiri sebagaimana yang telah di atur Kemenkes Nomor 187 tahun $2017^{9}$.

Pelaksanaan swamedikasi (pengobatan diri sendiri) dapat didukung dengan adanya tanaman obat itu sendiri. ${ }^{10}$ Cara untuk memperoleh tanaman obat dengan mudah salah satunya ialah warga dapat menanam tanaman tersebut di halaman sekitar rumah. Pembudidayaan tanaman obat dapat memberi keuntungan tersendiri bagi warga antara lain efektif waktu jika dibutuhkan segera, memberikan kesan asri pada halaman rumah karena rata-rata tanaman obat bewarna hijau, serta dapat meningkatkan derajat ekonomi. Lokasi mitra memiliki keunggulan sebagai kampung keluarga berencana (KB) dimana kaum wanita lebih banyak populasinya disana. Sehingga untuk meningkatkan produktifitas kaum ibu-ibu dan menaikan derajat perekonomian dapat dilakukan dengan cara memanfaatan tanaman obat tersebut. Hasil panen yang diperoleh dapat dijual kepada produsen jamu atau obat tradisional baik dalam kondisi basah maupun kering dan dapat dimanfaatkan untuk diri sendiri.

Lingkungan mitra yang memiliki lahan tanam sempit, dalam implementasi penanaman obat tradisional dimaksimalkan dengan cara menanam tanaman obat menggunakan pot gantung atau ditanam di pot-pot kecil dan disimpan di halaman rumah. Setelah tanaman mulai besar warga dapat memindahkanya di lahan yang lebih luas sehingga dapat dibudidayakan bersama warga lainya. Dengan adanya satu lahan yang berisi tanaman obat tradisional dapat memudahkan warga disekitar melakukan swamedikasi menggunakan tanaman tersebut. Didukung dengan sosialisasi diawal dapat mengedukasi warga untuk melakukan swamedikasi secara rasional dalam menggunakan tanaman obat yang berasal dari alam yang memiliki potensi sebagai obat.

Untuk memastikan tingkat kemandirian warga Kampung KB, tim melakukan home visit rumah warga. Hasilnya kegiatan ini sebagian warga sudah melakukan penanaman, penggolongan tanaman tardisional, serta mampu melakukan pengolahan dari hasil tanaman tersebut.. Contohnya warga

9 Departemen Kesehatan RI, Kepmenkes Nomor 187 Tabun 2017 tentang Formularium Ramuan Obat Tradisional Indonesia (Indonesia, 2017).

${ }^{10}$ Dale H. Clayton and Nathan D. Wolfe, "The Adaptive Significance of Self-Medication," Trends in Ecology \& Evolution 8, no. 2 (1993): 60-63. 


\section{ENGAGEMENT}

\section{Lurnal Pengabdian Kepada Masyarakat}

ISSN : 2579-8375 (Print)

ISSN : 2579-8391 (Online)
This work is licensed under a Creative Commons

Attribution-ShareAlike 4.0 International License.

CC BY SA

yang sudah memiliki tanaman obat memanfaatkanya dengan cara mengeringkan di halaman rumah menggunakan kain tipis untuk memperoleh simplisia. Simplisia yang diperoleh sebagian disimpan dan sebagian diserbuk untuk disedu sebagai seperti the, seperti sirih merah, jahe, dan temulawak.

Tanaman obat tradisional, terbagi menjadi tiga golongan yaitu jamu, obat herbal terstandar dan fitofarmaka. ${ }^{11}$ Masing-masing golongan tersebut memiliki logo dan karakteristik yang berbeda-beda yang masyarakat berhak untuk mengetahuinya. Obat tradisional memiliki tujuan sebagai upaya preventif, kuratif, rehabilitatif, paliatif dan promotif. Berdasarkan Keputusan Menteri Kesehatan Nomor 1076 tahun 2003, pengobatan tradisional merupakan salah satu upaya pengobatan atau perawatan selain diluar ilmu kedokteran dan atau ilmu keperawatan, yang masih banyak dimanfaatkan oleh masyarakat dalam pengobatan. Untuk mendukung kerasionalan penggunaan obat dalam kehidupan sehari-hari warga dibekali dengan buku saku resep obat berserta dosisnya. Riset yang dilakukan oleh Encang dkk. ${ }^{12}$ warga di Desa Cisondari Kabupaten Bandung proses pendokumentasian pengetahuan secara tulis tidak dilakukan, karena masyarakat memiliki budaya lisan yang kuat dibandingkan tulisan. Adanya buku saku, Warga diharapkan dapat menggunakan obat tradisional secara tepat dosis dan tepat indikasi sehingga dapat meminimalkan resiko efek samping yang akan timbul.
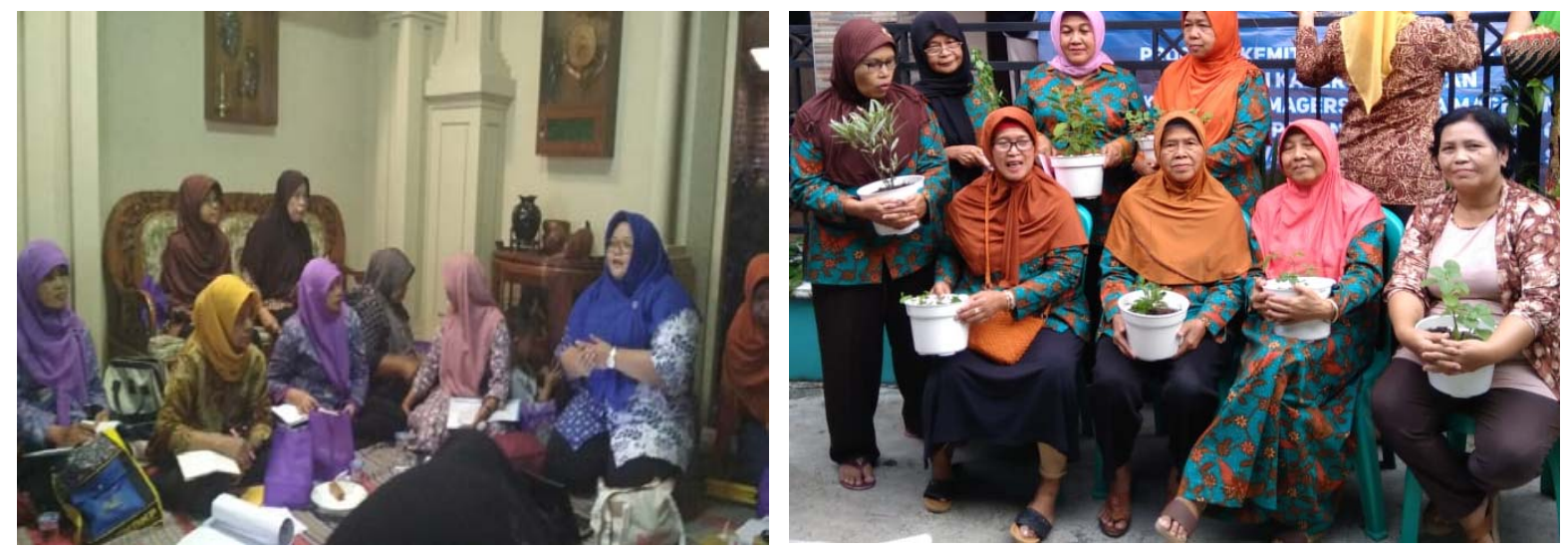

Gambar 1. Implementasi Pendampingan Swamedikasi Warga Kampung KB

\section{Kesimpulan}

11 Hedi R. Dewoto, "Pengembangan Obat Tradisional Indonesia Menjadi Fitofarmaka," Majalah Kedokteran Indonesia 57, no. 7 (2007): 205-211.

12 Encang Saepudin, Agus Rusmana, and Agung Budiono, "Penciptaan Pengetahuan Tentang Tanaman Obat Herbal Dan Tanaman Obat Keluarga," Jurnal Kajian Informasi \& Perpustakaan 4, no. 1 (2016): 95-106.

Volume 3, Number 2, November 2019| 214 Penggunaan Obat Rasional Dan Pemanfaatan Tanaman Obat Tradisional Sebagai Terapi Swamedikasi (Pengobatan Sendiri) Di Kelurahan Magersari Kota Magelang. 


\section{ENGAGEMENT}

Lurnal Pengabdian Kepada Masyarakat

ISSN : 2579-8375 (Print)

ISSN : 2579-8391 (Online)
This work is licensed under a Creative Commons

Attribution-ShareAlike 4.0 International License.

CC BY SA

Kegiatan pengabdian di Kampung KB Kelurahan Magersari yang dilakukan selama 3 bulan berbasis komunitas meningkatkan partisipasi warga masyarakat dalam memanfaatkan tanaman obat tradisional untuk pengobatan diri sendiri (swamedikasi). Pengetahuan dan pemahaman warga yang berkaitan dengan obat tradisional cenderung meningkat. Hal tersebut ditandai dengan pemahaman warga mengenai pengertian obat tradisional, jenisnya, takaran pakai, cara mendapatkan, cara mengolah, cara mengkonsumsi, cara menyimpan dan cara membuang obatobatan. Bibit tanaman obat yang ada diwarga berkembang dengan baik dan disimpan dimasingmasing rumah warga. Sudah ada beberapa warga yang mencoba terapi menggunakan ramuan obat tradisional yang bersumber dari KepMenKes nomor 187 tahun 2017. Contohnya untuk mengobati nyeri pada gigi, radang tenggorokan, dan batuk serta membuat simplisia. Masyarakat juga mendapatkan tambahan informasi mengenai khasiat dan fungsi tanaman alam Indonesia yang sebagian sudah dipaparkan dalam bentuk buku saku dan presentasi yang dapat digunakan sebagai salah satu sumber informasi untuk swamedikasi.

\section{Daftar Referensi}

Chambers, Robert. "The Origins and Practice of Participatory Rural Appraisal." World development 22, no. 7 (1994): 953-969.

Clayton, Dale H., and Nathan D. Wolfe. "The Adaptive Significance of Self-Medication." Trends in Ecology \& Evolution 8, no. 2 (1993): 60-63.

Departemen Kesehatan RI. Kepmenkes Nomor 187 Tabun 2017 Tentang Formularium Ramuan Obat Tradisional Indonesia. Indonesia, 2017.

Dewoto, Hedi R. "Pengembangan Obat Tradisional Indonesia Menjadi Fitofarmaka." Majalah Kedokteran Indonesia 57, no. 7 (2007): 205-211.

Kementerian Kesehatan RI. Peraturan Pemerintah RI No. 103 Tabun 2014 Tentang Pelayanan Kesehatan Tradisional. Indonesia, 2014.

Kementrian Kesehatan. PMK Nomor 6 Tahun 2016 Tentang Formularium Obat Herbal. Indonesia, 2016.

Kesehatan, Badan Litbang. “Laporan Riskesdas 2010.” Jakarta Badan Litbang Kesehat (2010).

Kesehatan, Kementerian. "Rencana Strategis Kementerian Kesehatan." Jakarta. Kementerian Kesehatan (2015).

Saepudin, Encang, Agus Rusmana, and Agung Budiono. "Penciptaan Pengetahuan Tentang Tanaman Obat Herbal Dan Tanaman Obat Keluarga." Jurnal Kajian Informasi \& Perpustakaan 4, no. 1 (2016): 95-106.

Volume 3, Number 2, November 2019| 215

Penggunaan Obat Rasional Dan Pemanfaatan Tanaman Obat Tradisional Sebagai Terapi Swamedikasi (Pengobatan Sendiri) Di Kelurahan Magersari Kota Magelang.

Ni Made Ayu Nila Septianingrum, Fitriana Yuliastuti, Widarika Santi Hapsari 


\section{ENGAGEMENT}

Lurnal Pengabdian Kepada Masyarakat

ISSN : 2579-8375 (Print)

ISSN : 2579-8391 (Online)
This work is licensed under a Creative Commons

Attribution-ShareAlike 4.0 International License.

CC BY SA

Sari, Siska Mayang, and Tengku Abdur Rasyid. "Pemanfaatan Tanaman Obat Keluarga (Toga) Pada Masyarakat.” Dinamisia: Jurnal Pengabdian Kepada Masyarakat 3 (2019).

Yulianto, Susilo. "Pengetahuan Masyarakat Tentang Taman Obat Keluarga Di Nglinggi, Klaten Selatan." Jurnal Kebidanan dan Kesehatan Tradisional 1, no. 2 (2016).

Yuliastuti, Fitriana, Widarika Shanti Hapsari, and Tria Mardiana. "GeMa CerMat (Gerakan Masyarakat Cerdas Menggunakan Obat) Bagi Guru Sekolah Dasar Kecamatan Magelang Selatan Kota Magelang." Community Empowerment 3, no. 2 (October 29, 2018): 34-37.

Chambers, Robert. "The Origins and Practice of Participatory Rural Appraisal." World development 22, no. 7 (1994): 953-969.

Clayton, Dale H., and Nathan D. Wolfe. "The Adaptive Significance of Self-Medication." Trends in Ecology \& Evolution 8, no. 2 (1993): 60-63.

Departemen Kesehatan RI. Kepmenkes Nomor 187 Tabun 2017 Tentang Formularium Ramuan Obat Tradisional Indonesia. Indonesia, 2017.

Dewoto, Hedi R. "Pengembangan Obat Tradisional Indonesia Menjadi Fitofarmaka." Majalah Kedokteran Indonesia 57, no. 7 (2007): 205-211.

Kementerian Kesehatan RI. Peraturan Pemerintah RI No. 103 Tabun 2014 Tentang Pelayanan Kesehatan Tradisional. Indonesia, 2014.

Kementrian Kesehatan. PMK Nomor 6 Tahun 2016 Tentang Formularium Obat Herbal. Indonesia, 2016.

Kesehatan, Badan Litbang. “Laporan Riskesdas 2010.” Jakarta Badan Litbang Kesehat (2010).

Kesehatan, Kementerian. "Rencana Strategis Kementerian Kesehatan." Jakarta. Kementerian Kesehatan (2015).

Saepudin, Encang, Agus Rusmana, and Agung Budiono. "Penciptaan Pengetahuan Tentang Tanaman Obat Herbal Dan Tanaman Obat Keluarga." Jurnal Kajian Informasi \& Perpustakaan 4, no. 1 (2016): 95-106.

Sari, Siska Mayang, and Tengku Abdur Rasyid. "Pemanfaatan Tanaman Obat Keluarga (Toga) pada Masyarakat." Dinamisia: Jurnal Pengabdian Kepada Masyarakat 3 (2019).

Yulianto, Susilo. "Pengetahuan Masyarakat Tentang Taman Obat Keluarga Di Nglinggi, Klaten Selatan." Jurnal Kebidanan dan Kesehatan Tradisional 1, no. 2 (2016).

Yuliastuti, Fitriana, Widarika Shanti Hapsari, and Tria Mardiana. "GeMa CerMat (Gerakan Masyarakat Cerdas Menggunakan Obat) Bagi Guru Sekolah Dasar Kecamatan Magelang Selatan Kota Magelang.” Community Empowerment 3, no. 2 (October 29, 2018): 34-37.

Volume 3, Number 2, November 2019| 216

Penggunaan Obat Rasional Dan Pemanfaatan Tanaman Obat Tradisional Sebagai Terapi Swamedikasi (Pengobatan Sendiri) Di Kelurahan Magersari Kota Magelang. 